\title{
Algorithmic Case Pedagogy, Learning and Gender
}

\author{
Robert Bromley (Corresponding author) \\ Professor of Accounting, Central Michigan University \\ 150 E. Bellows St., Mount Pleasant, MI 48859, USA \\ E-mail: robert.bromley@cmich.edu
}

\author{
Zhenyu Huang \\ Professor of Business Information Systems, Central Michigan University \\ 150 E. Bellows St., Mount Pleasant, MI 48859, USA \\ E-mail: huang1z@cmich.edu
}

Received: September 19, 2015 Accepted: November 1, 2015

Published: November 6, 2015

doi:10.5296/jei.v1i2.8333 URL: http://dx.doi.org/10.5296/jei.v1i2.8333

\begin{abstract}
Great investment has been made in developing algorithmically-based cases within online homework management systems. This has been done because publishers are convinced that textbook adoption decisions are influenced by the incorporation of these systems within their products. These algorithmic assignments are thought to promote learning while discouraging the practice of shirking student responsibility via the sharing of a common correct answer. Our paper describes the first testing of this method's effectiveness. The results indicate marked differences of the case's effects on male and female students. Significant improvements in learning were found for male students but not for female students.
\end{abstract}

Keywords: Algorithmic assignments, Gender, Online homework management

\section{Introduction}

This study extends the research in educational technology by testing the effectiveness of the algorithmic case methodology. This technique, related to computer assisted learning, generates a unique set of data for each student while addressing the same learning objectives. Research into this pedagogy is important because significant investment has been made in developing algorithmically-based assignments within online homework management (OHM) 
systems. This has been done because publishers are convinced that textbook adoption decisions are influenced by the incorporation of these systems within their products (Hahn, Fairchild, \& Dowis, 2013). Use of algorithmic homework has also been recommended in current academic literature (Khanlarian \& Singh, 2014, p. 144). Recent studies have investigated the effectiveness of online homework management (OHM) systems but none have addressed the educational efficacy of algorithmically generated homework.

Dillard-Eggers, Wooten, Childs, and Coker (2008), studied student attitudes and effort. They found a positive relationship between the amount of homework completed and course grade while controlling for prior grade point average. If online homework management (OHM) systems cause students to increase their effort, then it is thought that learning should also improve (Pascarella, 2004). Porter and Johnston (2006) found a positive association with the use of an online system and student performance. However Demirci (2007) found that lower cognitive functions were used when OHM problems were assigned to physics students compared to paper-based homework. Other research found no significant difference in business statistics student performance using an OHM system (Palocsay \& Stevens, 2008). Gaffney, Ryan and Wurst (2010) found that OHM systems did not increase student satisfaction nor did they provide strong evidence regarding student learning. This may be because they did not make the distinction between algorithmic and static assignments used in OHM systems. Clearly there is some ambiguity in the research regarding the effectiveness of these systems (Khanlarian \& Singh, 2014).

Our investigation expands this research by conducting an intra-medium study to determine the educational effectiveness of algorithmic assignments where the data is unique to each student compared with a static case with common correct answers. In the pages that follow, a review of the literature leading us to conduct this research will be discussed along with the hypotheses tested by our study. The experimental design, student demographics, and empirical results will be presented as well as our conclusions and recommendations for further research.

\section{Background and Literature Review}

Previous studies have shown that the use of the computer could comprise a valuable context for social interaction within groups (Crook, 1996; Fischer \& Reuber, 2011). However, other research has indicated that the results of working in a small collaborative group yields cognitive outcomes that can be matched or exceeded by the most competent member of the group (Barker \& Cagwin, 2005; Barron, 1992; Hastie, 1983; Hill, 1982; Klein, Erchul, \& Pridemore, 1994; Schwartz, 1999). This may be the result of pedagogy that allows most members of the group to shirk their cognitive duties by relying on the strongest group member (Johnson \& Johnson, 1990). Algorithmic assignments overcome this weakness by providing each student with a unique set of data while incorporating the same learning objectives for the entire class. Each student is then forced to actually do the work versus copy another student's answers. Student work and hence learning are thought to increase as a result (Pascarella, 2004). Our objective is to test this algorithmic pedagogy to determine its effectiveness on learning. 


\section{Ml Macrothink}

The findings of Flowers, Osterlind, Pascarella, and Source (2001) suggest that gender bias within class pedagogy may represent a significant deterrent to learning. In their study of over 18,000 students from 56 four-year post-secondary institutions, a significant gender effect was found on student learning. They found that the overall impact of college for women was significantly and substantially smaller than that for men. Arum and Roksa (2011) also found lower levels of female enrollment in courses in business, engineering, math and science courses. This may indicate that these areas of postsecondary education are structured toward masculine rather than feminine intellectual orientations and learning styles. A study by Singha, Bhadauriab, Jainc, and Gurungd (2013) found that women also experienced higher levels of spreadsheet anxiety than male students and had lower self-efficacy. The work of Farland-Smith (2015) suggests that gender bias affects the academic life of students especially that of underrepresented girls. These studies underscore the importance of assessing the neutrality of pedagogy toward gender as a result we have also investigated the effect of algorithmically generated assignments on learning and gender.

\section{Hypothesis Development}

To determine whether the goals of improved educational effectiveness as well as neutrality with respect to gender are accomplished, we conducted an intra-medium study to test whether an algorithmic assignment improves learning and investigate the aptitudinal-treatment interaction of the case on gender.

\subsection{Intra-Medium Study}

In the previous studies mentioned above (Barker \& Cagwin, 2005; Barron, 1992; Hastie, 1983; Hill, 1982; Klein et al., 1994; Schwartz, 1999) the research found that the most competent member of a group could match or exceed the cognitive outcomes of the entire group. We believe that this is caused by group members abdicating or shirking their cognitive duties by relying on the strongest or most competent group member. Our a priori thought is that the algorithmic pedagogy will overcome this problem by creating a unique set of data for each student that would compel each student to be independently and actively involved in the solution of their case while giving and receiving help from their peers. This would be consistent with Barfurth's (1995) findings that the inability of students to shirk their duty and copy from other students enhances goal congruence, which is a necessary component of collaborative learning. Students would be encouraged to focus on the problem-solving process rather than just the answer (Gilbert-MacMillan, 1983).

Our experiment used the three-step design of individual pretest, paired treatment and individual posttest developed by Doise and Mugny (1984). The algorithmic case was used by the treatment group while a static spreadsheet having the same learning objectives yet with a common solution was used for the control group. Given the expectations mentioned above, we propose the following hypotheses:

H1: The application of accounting knowledge to business events (the increase in posttest scores from pretest scores) will improve significantly more for students using the algorithmic case versus students using a static spreadsheet case. 


\subsection{Aptitudinal-Treatment Interaction}

Thompson's broad definition of aptitude supports including gender in an aptitudinal-treatment interaction study. Aptitude is considered to be "any characteristic of a person that forecasts his/her probability of success under a given treatment" (Thompson, Simonson, \& Hargrave, 1992). Based on findings of Flowers et al. (2001) and Arum and Roksa (2011) gender bias may have a detrimental effect on student learning. Since gender should be considered when choosing instructional material (Dunn, Hooks, \& Kohlbeck, 2014), the effect of algorithmic pedagogy on gender is investigated here. If this case is neutral with respect to gender, then the following hypothesis should be found to be true:

H2: The algorithmic case is neutral with respect to gender. That is, differences in learning will not be significant between male and female students using the algorithmic case compared with the static case.

\section{Methodology and Experimental Design}

The hypotheses described in the previous sections were tested in a classroom setting to promote the external validity of the study to that of a normal university setting. Approval was granted from the university's institutional review board prior to the research. One hundred forty six students were recruited from six sections of the second required course in introductory accounting (Concepts of Managerial Accounting) at an AACSB accredited university. The students were assigned to the control group or the treatment group based on the class section they attended and were encouraged to interact with the students in their class as they solved the case.

Opdecam and Everaert (2012) found that forcing students into arbitrary groups does not result in optimal collaboration. Holt, Michael, and Godfrey (1997) also found that in the combination of heterogeneous student desires, large class sizes and limited resources, one method of class organization cannot optimize the use of time for all students. Following these recommendations we did not force students into study groups but encouraged them to work with others in their class based on their individual academic needs and learning styles. Since the majority of homework assignments are completed by students in this way we believe this also adds to the external validity of our study.

\subsection{Algorithmic Case}

An algorithmic case was developed to test our hypothesis. Learning objectives requiring the application of general concept knowledge to problem-based situations were designed for an introductory financial accounting course. Since many researchers in education have found assignments of this nature to be most meaningful (Johnstone \& Biggs, 1998), the case should outline the boundaries of Vygotsky's (1978) “zone of proximal development." If our theory is correct, the students using the algorithmic case should learn more than students doing the same problem with static data where the common solution is easily shared allowing students can evade their responsibilities for doing the assignment.

Our case was created using Visual Basic for Applications (VBA) in Excel. It is similar to a 
typical introductory financial accounting assignment requiring students to apply accrual accounting concepts to a series of 12 business events including changes in resources resulting from exchange, consumption and distribution. The case was used here as a review of concepts covered in the first course in accounting. Use of this generic case adds to our study's external validity by not tying the results of our research to one specific textbook's online homework management system.

When the case file is first opened, the VBA program solicits information concerning the student's name, student number and class section. The case is then initialized for that student providing a unique working trial balance and problem instructions which cannot be changed. Each student must then apply the accounting concepts mentioned above to record the appropriate adjustments in the working trial balance. Since each correct entry is unique, it is thought that students will learn more because they will be compelled to personally complete the assignment while they receive help and actively participate with others applying the general concept knowledge to their specific case. An additional file was also created to grade the students' work. The Visual Basic algorithms were designed to improve feedback response time, efficiency and accuracy over manually graded cases. The case is shown in Appendix 1 and is available upon request.

\subsection{Experimental Design and Procedures}

The experiment included four procedural stages (Table 1). They were based on the classic three-step design of individual pretest, paired treatment (stages 2 and 3) and individual posttest developed by Doise and Mugny (1984). The first day of class an 18 point pretest was administered to measure the student's base knowledge of accounting and solicit their demographics. The construct validity of the questions was tested using a standard index of discrimination measure. Content validity was established by using questions that addressed the essential topics covered by popular introductory financial accounting textbooks. A copy of the survey instrument is included in Appendix 2.

Table 1. Experimental design and procedures

\begin{tabular}{|l|l|l|}
\hline Procedural Stage: & Control Group & Treatment Group \\
\hline $\begin{array}{l}>\text { Pretest: test of the application of accounting concept } \\
\text { knowledge, and student self-reported demographics. }\end{array}$ & Pretest & Pretest \\
\hline $\begin{array}{l}>\text { Training: spreadsheet use and file backup, review of } \\
\text { financial accounting concepts and the recording process. } \\
\text { Exchange of contact information. }\end{array}$ & Training & Training \\
\hline$>$ Spreadsheet Case & Static Data & Algorithmic Data \\
\hline $\begin{array}{l}>\text { Posttest: surprise test of the application of accounting } \\
\text { concept knowledge. }\end{array}$ & $\begin{array}{l}\text { Posttest } \\
\text { Survey }\end{array}$ & $\begin{array}{l}\text { Posttest } \\
\text { Survey }\end{array}$ \\
\hline
\end{tabular}


During the second class period the students were given a demonstration as to how to initialize the Excel spreadsheet with their name, student number and class section number. They were shown how the working trial balance spreadsheet worked, as well as how to enter journal entry amounts and journal entry reference numbers into the cells. The method for making backup copies of their worksheet file was also described. After these technical issues were addressed the students were given a review of financial accounting and the recording process covered in their first accounting course. The concepts reviewed included revenue recognition, the matching principle, as well as the definitions of assets, liabilities and equity. Rules for increasing and decreasing account balances were also presented in class and placed on the course Blackboard website. The students were then instructed to apply these concepts to the business events in the case by entering the appropriate adjusting entries and adequate explanations. Students were encouraged to work together and time was given at the end of the class to permit the students to exchange phone numbers, E-mail addresses and other contact information so that they could collaborate voluntarily outside of class.

The third class hour began with a short class discussion concerning the case; however, the professor provided no specific solutions. The rest of the class hour was devoted to group interaction and students were again encouraged to collaborate outside of class. The cases were submitted electronically to Blackboard prior to the fourth class period. A surprise 18 point posttest was given at the beginning of that class. It contained the same pretest questions measuring their ability to apply concept knowledge to business events. No feedback was given to the students regarding the case or pretest until after the posttest was administered.

\subsection{Controls for Consistency}

A number of procedures were implemented into the methodology to insure consistency between the control and treatment groups. The same 12 business events and set of accounts were used for both groups. The same instructor was used to describe the cases and provide a review of financial accounting concepts and the reporting process. The presentations were scripted and timed to insure homogeneity from one session to another. Standard classrooms with similar presentation equipment were used to control for novelty. The same computer labs were made available to all of the students. The length of the assignment was also held constant to control for maturation. The selection of control and treatment groups was switched each semester to offset differences in student class time preferences. The difference between the groups was that students in the treatment group were informed that each student was working with unique values while students in the control group knew that the values in their spreadsheets were the same.

\subsection{Student Demographics}

The participants reported an overall cumulative grade point average of 3.18 which is representative of most students in the university's undergraduate business program. The grade point averages for the treatment group and the control group were 3.17 and 3.20 respectively. $t$-tests assuming equal variances between groups indicated that there was no significant difference between the groups' GPAs $t(119)=.330, p=.742$. Also the reported average grade earned by the students in their introductory financial accounting course (Acc250) was 2.81 
with the average for the treatment group and the control group being 2.71 and 2.93 respectively. $t$-tests assuming equal variances between groups indicated no significant difference between the groups $t(109)=1.84, p=.069)$.

Although it would have been preferable to have actual rather than self-reported grade point averages, there is compelling evidence supporting the veracity of student self-reported grades. Trusheim's (1994) study of student reported SAT scores and Baird's (1976) review of 40 years of research covering student self-reported grades found strong correlations between the student reported and actual values.

The distribution of gender between treatment and control groups was also evaluated. The treatment group had 17 females (24\%) and 54 males (76\%) and the control group had 21 females $(28 \%)$ and 54 males (72\%). A chi-square test indicates that these differences were not significant, $x^{2}(1, \mathrm{~N}=146)=.312, p=.577$, Cramer's $\mathrm{V}=.046$.

The other demographic characteristics obtained were the student's anticipated major and their class status. The anticipated majors reported by the students included majors in accounting, economics, entrepreneurship, finance, hospitality services administration, human resource management, management, management information systems and marketing. They were representative of our business students in general and no significant differences were noted between the treatment and the control groups, $x^{2}(8, \mathrm{~N}=145)=14.135, p=.078$, Cramer's V $=.312$. The distribution of student class standing (sophomore, junior or senior) was also not significantly different between groups, $x^{2}(2, \mathrm{~N}=146)=5.450, p=.066$, Cramer's $\mathrm{V}=.193$. The frequency distributions are shown in Appendix 3.

One measure did indicate a significant difference between the treatment and control groups. The average final course grade (Acc255) was 2.42 and represents a measure of student scholarship. The average grades for the treatment group and the control group were 2.15 and 2.67 respectively. $t$-tests assuming equal variances between groups indicates a significant difference between the groups $t(144)=2.844, p=.005, d=.470$. This difference will be controlled in the regression study discussed in the empirical results section.

Based on these results we believe that the students included in our samples are representative of most students taking introductory accounting courses. We also find them to possess adequate general academic skills.

\section{Empirical Results}

Comparisons of the pre and posttest scores measuring the students' ability to apply accounting concept knowledge to economic events indicates that male students using the algorithmic case learned significantly more than male students in the control group. However, the results were not consistent with female students. In the paragraphs that follow the results of our intra-medium and the aptitudinal-treatment interaction studies will be more fully described.

\subsection{Intra-Medium Findings}

Comparisons between the treatment and control groups' changes in learning (post-test minus 
pre-test (Note 1)) indicate that the differences between the treatment group that used the algorithmic case $(\mathrm{M}=2.61, \mathrm{SD}=2.549)$ and control group using the static case $(\mathrm{M}=1.91$, $\mathrm{SD}=1.876$ ) were not significantly different assuming unequal variance, $t(128.3)=-1.878, p$ $=0.063$. Therefor we reject H1: The application of accounting concept knowledge to business events (the increase in posttest scores from pretest scores) will improve significantly for students using the algorithmic case versus students using a static spreadsheet case.

\subsection{Aptitudinal-Treatment Interaction}

When gender is included in the analysis, the results indicate that the algorithmic case was associated with significant improvements in learning for men but not for women. An analysis of the female students separately indicated that the net change in learning was not significant between the treatment group $(\mathrm{M}=1.94, \mathrm{SD}=2.410)$, and the control group assuming equal variances $(\mathrm{M}=2.05, \mathrm{SD}=2.313), t(36)=.138, p=.891$. The treatment group actually had lower average scores.

Conversely, the analysis of the male student's change in learning found that the treatment group $(\mathrm{M}=2.82, \mathrm{SD}=2.578)$, had a significant increase in learning compared to the control group assuming unequal variances $(\mathrm{M}=1.85, \mathrm{SD}=1.698), t(91.7)=-2.293, p=.024$, effect size $d=-.441$. Cohen's $d$ suggests a medium size effect indicating that the treatment group would have changes in learning that are .441 standard deviations higher than the control group (Cohen, 1988).

\subsubsection{Analysis of Variance - Male Student Learning}

To study male learning further a $2 \times 2$ one-between - one-within ANOVA on learning was conducted with group (control and treatment) as the between subjects factor and learning over time (pretest and posttest) as the within subjects factor. The results indicate a significant main between-subject effect for the control and treatment groups, $\mathrm{F}(1,106)=5.999, \mathrm{p}<.05$, partial $\eta^{2}=.054$. A significant main within-subject effect was also indicated for learning over time, Greenhouse-Geisser adjusted $\mathrm{F}(1,106)=123.431, \mathrm{p}<.01$, partial $\eta^{2}=.538$, as well as a significant interaction between learning over time and group, Greenhouse-Geisser adjusted $\mathrm{F}$ $(1,106)=5.256, \mathrm{p}<.05$, partial $\eta^{2}=.047$. The results are consistent with the $t$ test of male learning above.

\subsubsection{Regression Analysis of Combined Group}

A regression analysis was also conducted on the combined group of male and female students to expand our understanding of the effect of gender on student learning. Gender, Group (control or treatment), Acc250 and Acc255 grades, as well as Pretest scores were included in a multiple regression to predict Posttest learning for the pooled sample of all students. The results were significant $F(5,105)=31.006, p<.001, R^{2}=.596$. Gender, Acc250 Grade and Pretest were found to be significant predictors of the Posttest measure of learning while Group (control and treatment), and Acc255 Grade was not significant in the model.

Tests for multicollinearity within our model indicate that the independent variables are not significantly collinear and are well within the acceptable range of the variance inflation factor. 


\section{Ml Macrothink}

The Durbin-Watson statistic of 2.032 indicates that the residuals are not correlated serially. Also a review of the residual scatterplots does not indicate the presence of serious heteroscedasticity across levels of the posttest values.

These findings confirm the results of the independent $t$ tests. The overall effect of the algorithmic assignment becomes insignificant when gender is included in the regression model. As the $t$ tests indicate, this is because the algorithmic case has different effects on males and females. Based on the consistent results of our independent $t$-tests, ANOVA and multiple regression studies we reject $\mathbf{H} 2$ and find that the algorithmic case is not neutral with respect to gender.

\section{Implications}

Our findings suggest that algorithmic cases significantly improve learning for men but not for women. Many studies focusing on gender note there are significant differences between men and women in their academic delay of gratification. Academic delay of gratification refers to students' postponement of immediately available opportunities to satisfy impulses in favor of pursuing academic goals (Bembenutty, 2009). In a study of students' use of stress-reducing learning strategies on their preference for delaying gratification Bembenutty (2008) found that higher willingness to delay gratification was associated with females. Similar results were found by El-Fattah and AL-Nabhani (2012) when they examined the differences between female and male high school students.

The algorithmic case methodology limits students' opportunity for immediate gratification by preventing them from copying a common answer and requiring them to actually do the assignment. Based on the findings of Bembenutty (2008 and 2009) and El-Fattah and AL-Nabhani (2012) this algorithmic pedagogy may have a more significant effect on men who are less willing to delay gratification than women and explain the statistical results of our study.

The empirical literature regarding the effects of technology on learning is at best, mixed. Serious questions have been raised concerning the cost-effectiveness of educational technology (Bryant \& Hunton, 2000; Levin \& Meister, 1985). In addition, a review of early studies led Clark to conclude that technology did not influence learning (1983). As a result of these findings great care was taken to control for confounding external influences and practice effects common to studies of this nature.

\section{Suggestions for Further Research}

We must admit that "For now we see through a glass darkly..." (Note 2). Our findings are not conclusive with respect to students' day-to-day learning throughout college where learning is more of a continuous and interrelated process. A longitudinal study incorporating many such cases would provide more reliable insight and support for this method. Our study also did not evaluate other related benefits or problems of algorithmic cases such as student satisfaction or levels of collaboration. Curriculum design requires the cooperation among professors and developers of educational systems as well as a shared vision of objectives. We hope that this study will lead to more research and development of new pedagogy that improves learning, 
as well as collaborative student interaction.

\section{Acknowledgements}

The authors would like to thank the anonymous reviewers for their suggestions and to acknowledge Sanjay Mudagol, Chandra Sarker, Wei Wang, and William L. Wohlgamuth, II, for their technical assistance. We would also like to thank the following CMU alumni for their indirect financial support of this research: Al Cambridge, and Mike O'Donnell.

\section{References}

American Institute of Certified Public Accountants (AICPA). (1999). Core Competency Framework for Entry into the Accounting Profession. Accounting Education. Retrieved from http://www.aicpa.org/interestareas/accountingeducation/resources/pages/corecompetency.asp $\mathrm{x}$

Arum, R., \& Roksa, J. (2011). Academically Adrift: Limited Learning on College Campuses. Chicago: University of Chicago Press. http://dx.doi.org/10.7208/chicago/9780226028576.001.0001

Baird, L. (1976). Using self-reports to predict student performance. Research Monograph No. 7. New York: College Entrance Examination Board.

Barfurth, M. (1995). Understanding the collaborative learning process in a technology rich environment: The case of children's disagreements. In J. Schnase \& L. Cunnius (Eds.), Proceedings of the First International conference on Computer Support for Collaborative Learning (pp. 8-13). Bloomington, IN: Lawrence Erlbaum Associates. http://dx.doi.org/10.3115/222020.222042

Barker, K., \& Cagwin, D. (2005). Group versus individual learning of quantitative accounting topics: effects on test performance in the first-year accounting course. Academy of Educational Leadership Journal, 9(1), 37-49.

Barron, B. (1992). Collaborative problem solving: Is team performance greater then what is expected from the most competent member? Doctoral dissertation, Vanderbilt University Press, Nashville.

Bembenutty, H. (2008). Academic delay of gratification and expectancy-value. Personality and Individual Differences, 44(1), 350-352. http://dx.doi.org/10.1016/j.paid.2007.07.025

Bembenutty, H. (2009). Test anxiety and academic delay of gratification. College Student Journal, 43(1), 10-12.

Bryant, S., \& Hunton, J. E. (2000). The Use of Technology in the Delivery of Instruction: Implications for Accounting Educators and Education Researchers. Issues in Accounting Education, 15(1), 129-162. http://dx.doi.org/10.2308/iace.2000.15.1.129

Clark, R. E. (1983). Reconsidering research on learning from media. Review of Educational Research, 53(4), 445-447. http://dx.doi.org/10.3102/00346543053004445 
Cohen, J. (1988). Statistical power analysis for the behavioural sciences (2nd ed.). Hillsdale, NJ: Lawrence Erlbaum Associates.

Crook, C. (1996). Computers and the Collaborative Experience of Learning. London: Routledge Press.

Demirci, N. (2007). University students' perceptions of web-based vs. paper-based homework in a general physics course. Eurasia Journal of Mathematics, Science and Technology Education, 3(1), 29-34.

Dillard-Eggers, J., Wooten, T., Childs, B., \& Coker, J. (2008). Evidence on the effectiveness of on-line homework. College Teaching Methods and Styles Journal, 4(5), 9-16.

Doise, W., \& Mugny, G. (1984). The Social Development of the Intellect. Oxford: Pergamon.

Dunn, M., Hooks, K., \& Kohlbeck, M. (2014). Preparing Future Accounting Faculty Members to Teach. Issues in Accounting Education, In-Press. http://dx.doi.org/10.2308/iace-50989

Farland-Smith, D. (2015). Struggles of Underrepresented Girls as They Become Women: Understanding How Race \& Gender that Impact Personal Science Identity Construction. Journal of Educational Issues, 1(1). http://dx.doi.org/10.5296/jei.v1i1.7501

Fischer, E., \& Reuber, A. (2011). Social interaction via new social media: (How) can interactions on Twitter affect effectual thinking and behavior? Journal of Business Venturing, 26(1), 1-18. http://dx.doi.org/10.1016/j.jbusvent.2010.09.002

Flowers, L., Osterlind, S., Pascarella, S., \& Source, E. (2001). How much do students learn in college? The Journal of Higher Education, 72(5), 565-583. http://dx.doi.org/10.2307/2672881

Gaffney, M., Ryan, D., \& Wurst, C. (2010). Do on-line homework systems improve student performance? In A. H. Catanach, \& D. Feldman (Eds.), Advances in Accounting Education (11th ed., pp. 49-68). Bingley, U.K.: Emerald Group Publishing Limited.

Gilbert-Macmillan, K. M. (1983). Mathematical Problem-Solving in Cooperative Small Groups and Whole Class Instruction. Doctoral dissertation, Stanford University. Dissertation Abstracts International, 4409A.

Hahn, W., Fairchild, C., \& Dowis, W. (2013). Online Homework Managers and Intelligent Tutoring Systems: A Study of Their Impact on Student Learning in the Introductory Financial Accounting Classroom. Issues in Accounting Education, 28(3), 513-535. http://dx.doi.org/10.2308/iace-50441

Hastie, R. (1983). Experimental evidence on group accuracy. In B. Grofman \& G. Owen (Eds.), Information Pooling and Group Decision Making (pp. 129-157). Greenwich, CT: JAI Press.

Hill, G. (1982). Group versus individual performance: Are $\mathrm{N}+1$ heads better than one? Psychological Bulletin, 91, 517-539. http://dx.doi.org/10.1037/0033-2909.91.3.517 
Holt, D., Michael, S., \& Godfrey, J. (1997). The case against cooperative learning. Issues in Accounting Education, 12(1), 191-193.

Institute of Internal Auditors (IIA). (2009). Internal Auditor Competency Framework. Altamonte Springs, FL: The Institute of Internal Auditors.

Institute of Management Accountants (IMA). (1999). Counting More Counting Less: Transformations in the Management Accounting Profession. Montvale, NJ: IMA.

Johnson, D., \& Johnson, R. (1990). Cooperative learning and achievement. In S. Sharon (Ed.), Cooperative Learning: Theory and Research. New York, NY: Praeger, Inc.

Johnstone, K. M., \& Biggs, S. F. (1998). Problem-based learning: Introduction, analysis, and accounting curricula implications. Journal of Accounting Education, 16(4), 407-427. http://dx.doi.org/10.1016/S0748-5751(98)00026-8

Khanlarian, C. J., \& Singh, R. (2014). An Exploratory Study of the Online Learning Environment. Issues in Accounting Education, 29(1), 117-147. http://dx.doi.org/10.2308/iace-50614

Klein, J. D., Erchul, J. A., \& Pridemore, D. R. (1994). Effects of individual versus cooperative learning and type of reward on performance and continuing motivation. Contemporary Educational Psychology, 19, 24-32. http://dx.doi.org/10.1006/ceps.1994.1003

Lehman, M., \& Malmberg, K. (2009). A global theory of remembering and forgetting from multiple lists. Journal of Experimental Psychology: Learning, Memory, and Cognition, 35(4), 970-988. http://dx.doi.org/10.1037/a0015728

Levin, H., \& Meister, G. (1985). Educational Technology and Computers: Promises, Promises, Always Promises. Project report No. 85-A13. Center for Educational Research. Stanford: Stanford University.

Opdecam, E., \& Everaert, P. (2012). Improving Student Satisfaction in a First-Year Undergraduate Accounting Course by Team Learning. Issues in Accounting Education, 27(1), 77. http://dx.doi.org/10.2308/iace-10217

Palocsay, S. W., \& Stevens, S. P. (2008). A study of the effectiveness of web-based homework in teaching undergraduate business statistics. Decision Sciences Journal of Innovative Education, 6(2), 213-343. http://dx.doi.org/10.1111/j.1540-4609.2008.00167.x

Pascarella, A. M. (2004). The influence of web-based homework on quantitative problem-solving in a university physics class. Proceedings of the National Association for Research in Science Teaching, 2004 Annual Meeting. Vancouver, BC, Canada.

Potter, B. N., \& Johnston, C. G. (2006). The effect of interactive on-line learning systems on student learning outcomes in accounting. Journal of Accounting Education, 24(1), 16-34. http://dx.doi.org/10.1016/j.jaccedu.2006.04.003

Schwartz, D. (1999). The Productive Agency that Drives Collaborative Learning. In P. Dillenbourg (Ed.), Collaborative Learning: Cognitive and Computational Approaches (pp. 
197-218). NY, NY: Pergamon.

Singha, A., Bhadauriab, V., Jainc, A., \& Gurungd, A. (2013). Role of gender, self-efficacy, anxiety and testing formats in learning spreadsheets. Computers in Human Behavior, 29(3), 739-746. http://dx.doi.org/10.1016/j.chb.2012.11.009

Thompson, A. D., Simonson, M. R., \& Hargrave, C. P. (1992). Educational Technology: A Review of the Research (pp. 17-18). Washington, D.C.: Association for Educational Communications and Technology.

Trusheim, D. (1994). How valid is self-reported financial aid information? Research in Higher Education, 35, 335-348. http://dx.doi.org/10.1007/BF02496827

Vygotsky, L. (1978). Mind in Society (pp. 86-87). Cambridge, MA: Harvard University Press.

\section{Notes}

Note 1. The pretest scores for the combined sample ranged from 1 to $17(\mathrm{M}=10.79, \mathrm{SD}=$ 3.20) with one student answering one question correctly and one student earning a score of 17. The posttest score distribution ranged from 5 to $18(\mathrm{M}=13.04, \mathrm{SD}=2.77)$ with one student earning a score of 5 and three students earning a score of 18 . Analysis of the frequency of the values of pretest and posttest scores indicates no scale attenuation.

Note 2. $1^{\text {st }}$ Corinthians 13:12.

\section{Appendix}

Appendix 1. Pathfinder Algorithmic Case

$>$ Student Identification Sheet

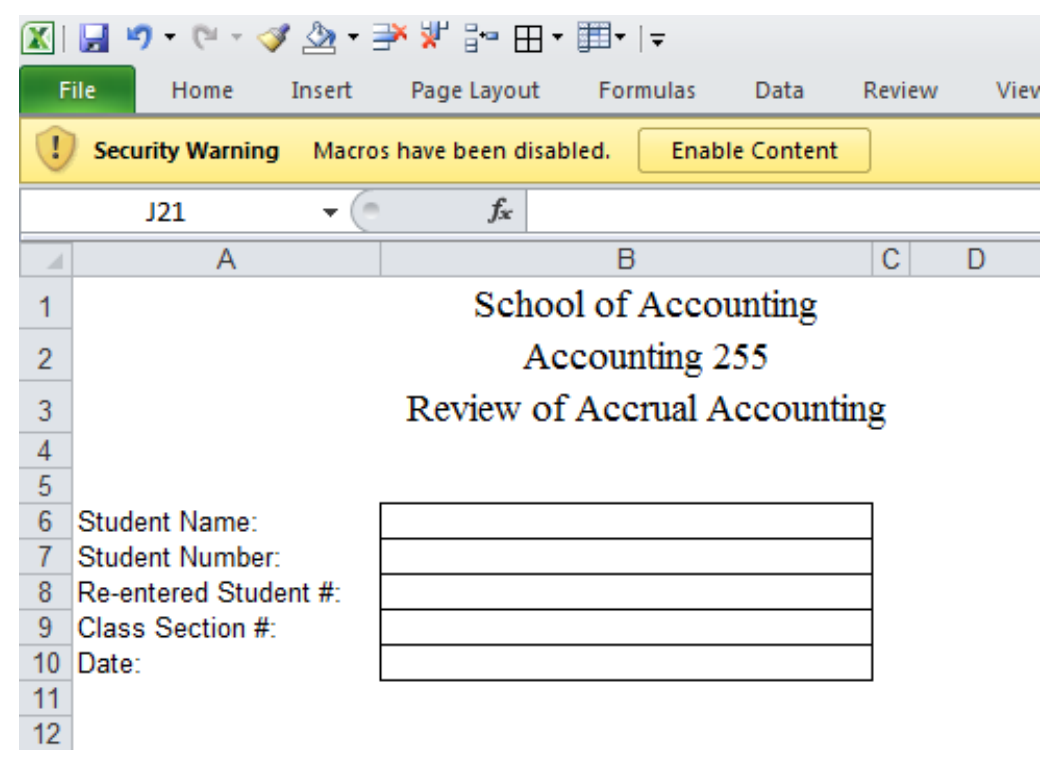




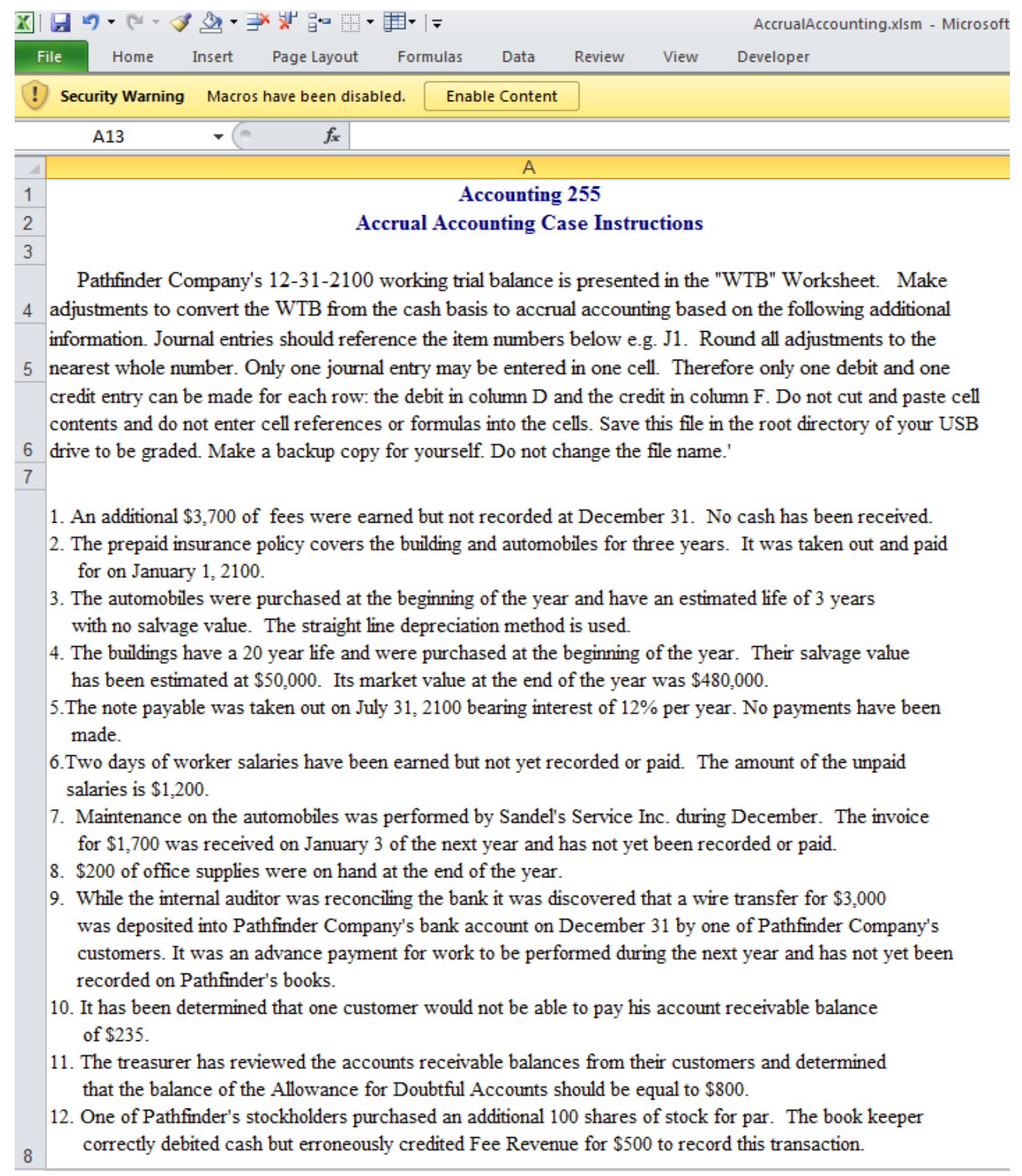


Working Trial Balance

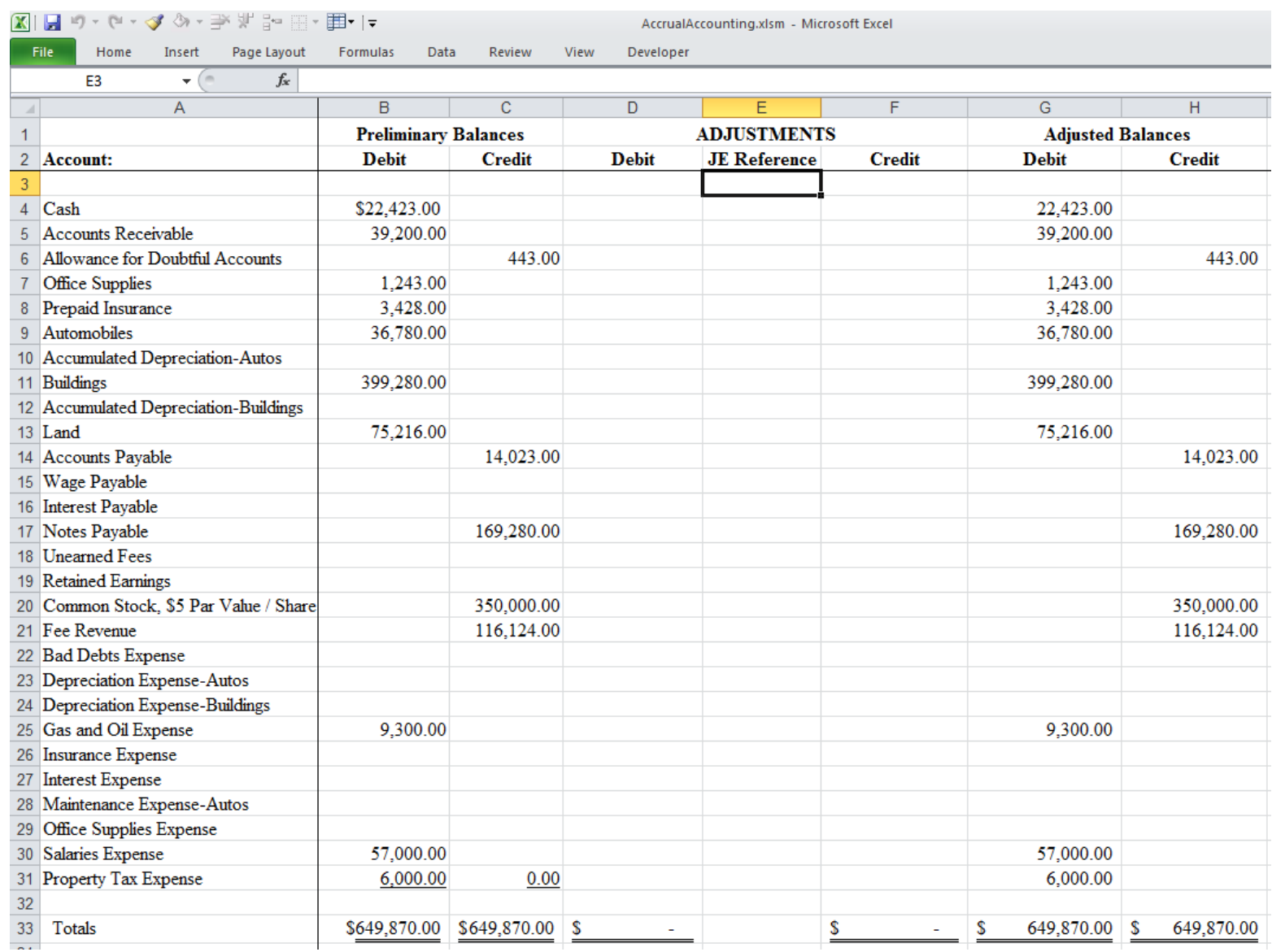

\section{Appendix 2. Pretest Instrument}

\section{Accounting 255 Pre-test Student Assessment Questions}

Instructions: Enter your name in the space provided above. Use a \# 2 pencil to blacken the appropriate circle on the separate answer sheet to indicate your name, global ID, and answers. Mark only one answer for each item.

Accounting Knowledge Assessment: Please select the most correct answer to the questions below.

1. One of the company's owners purchased an additional 100 shares of stock for par. The payment was for $\$ 30,000$. The correct journal entry should be:

A. Increase (debit) Cash by $\$ 30,000$ and increase (credit) Revenue by $\$ 30,000$.

B. *Increase (debit) Cash by $\$ 30,000$ and increase (credit) Common Stock by $\$ 30,000$.

C. Increase (debit) Accounts Receivable by $\$ 30,000$ and increase (credit) Deferred Revenue by $\$ 30,000$.

D. Increase (debit) Accounts Payable by $\$ 30,000$ and increase (credit) Assets by $\$ 30,000$.

E. No journal entry is necessary. 
2. Fee revenue has been earned but the payment has not been received. The revenue has also not been recorded. The correct entry should be:
A. Increase (credit) Accounts Payable and decrease (debit) Unearned Fees.
B. *Increase (debit) Accounts Receivable and increase (credit) Fee Revenue.
C. Increase (debit) Cash and increase (credit) Fee Revenue.
D. Decrease (debit) Accounts Payable and increase (credit) Unearned Fees.
E. Increase (debit) Cash and decrease (credit) Accounts Receivable.

3. An insurance policy was taken out and paid for on January 1. Cash was decreased and Prepaid Insurance was increased by $\$ 3,600$. The policy covers a 3 year period. The correct journal entry at December 31, the end of the first year should be:
A. Increase (debit) Insurance Expense and decrease (credit) Prepaid Insurance by $\$ 3,600$.
B. Increase (debit) Prepaid Insurance and decrease (credit) Insurance Expense by $\$ 1,200$.
C. Increase (debit) Cash and decrease (credit) Prepaid Insurance by $\$ 2,400$.
D. Increase (debit) Insurance Expense and decrease (credit) Cash by $\$ 3,600$.
E. *Increase (debit) Insurance Expense and decrease (credit) Prepaid Insurance by $\$ 1,200$.

4. A Building was purchased on January 1 at a cost of $\$ 440,000$. It has an estimated useful life of 20 years and a $\$ 40,000$ salvage value. Its current market value at the year-end is $\$ 480,000$. The correct entry at the end of this year to record the use of the building should be:
A. Increase (debit) Depreciation Expense by $\$ 22,000$ and increase (credit) Accumulated Depreciation by $\$ 22,000$.
B. Increase (debit) Depreciation Expense by $\$ 22,000$ and decrease (credit) Cash by $\$ 22,000$.
C. Increase (debit) Building by $\$ 40,000$ and increase (credit) Gain on Building by $\$ 40,000$.
D. *Increase (debit) Depreciation Expense by $\$ 20,000$ and increase (credit) Accumulated Depreciation by $\$ 20,000$.
E. Decrease (debit) Accumulated Depreciation by $\$ 20,000$ and increase (credit) Depreciation Expense by $\$ 20,000$.

5. Select the statement below about the accrual basis of accounting that is false.
A. Events that change a company's financial statements are recorded in the periods in which the events occur.
B. Revenue is recognized in the period in which it is earned.
C. The accrual basis of accounting is in accordance with generally accepted accounting principles.
D. *Revenue should be recorded when the cash is received and expenses should be recorded when cash is paid.




\section{Macrothink}

6. A note payable for $\$ 100,000$ was taken out on July 31 of this year bearing interest of $12 \%$ annually. The interest payments are on January 31 and July 31 . What journal entry is needed at December 31, the end of the year?

A. *Increase (debit) Interest Expense by $\$ 5,000$ and increase (credit) Interest Payable by $\$ 5,000$.

B. Increase (debit) Interest Expense by $\$ 6,000$ and decrease (credit) Cash by $\$ 6,000$.

C. Increase (debit) Interest Expense by $\$ 12,000$ and increase (credit) Interest Payable by $\$ 12,000$.

D. Increase (debit) Interest Expense by $\$ 6,000$ and increase (credit) Interest Payable by $\$ 6,000$.

E. No journal entry should be made until the cash is paid.

7. At the end of the year, two days of worker salaries have been earned but the company has not yet recorded or paid them. The amount of the unpaid salaries is $\$ 1,200$. The journal entry that should be made at the end of the year is:

A. Increase (debit) Salaries Expense by $\$ 1,200$ and decrease (credit) Cash by $\$ 1,200$.

B. Increase (credit) Salaries Revenue by $\$ 1,200$ and increase (credit) Salaries Receivable by $\$ 1,200$.

C. *Increase (debit) Salaries Expense by $\$ 1,200$ and increase (credit) Salaries Payable by $\$ 1,200$.

D. Increase (debit) Salaries Expense by $\$ 1,200$ and increase (debit) the Allowance for uncollectible wages by $\$ 1,200$.

E. No journal entry should be made until the cash is paid.

8. Maintenance on the company's automobiles was performed by Joe's Service Station on December 21, 2010. The invoice for $\$ 1,700$ was received on January 3 of the next year and has not been recorded or paid. The correct journal entry that should be made at the 2010 year end is:

A. Increase (debit) Auto Repair Expense by $\$ 1,700$ and increase (credit) Cash by $\$ 1,700$.

B. Increase (debit) Prepaid Auto Repairs by $\$ 1,700$ and decrease (credit) Cash by $\$ 1,700$.

C. Increase (debit) Automobiles by $\$ 1,700$ and increase (credit) Accounts Payable by $\$ 1,700$.

D. Increase (debit) Automobiles by $\$ 1,700$ and increase (credit) Accumulated Depreciation by $\$ 1,700$.

E. *Increase (debit) Auto Repair Expense by $\$ 1,700$ and increase (credit) Accounts Payable by $\$ 1,700$. 
9. At the end of the year it was discovered that a customer of the company had made a $\$ 500$ wire transfer to the company's bank account as an advance payment for work to be performed during the next year. This deposit of cash has not been recorded. The correct journal entry that should be made at the end of the year is:
A. Increase (debit) Accounts Receivable by $\$ 500$ and increase (credit) Revenue by $\$ 500$.
B. Increase (debit) Cash by $\$ 500$ and increase (credit) Revenue by $\$ 500$.
C. Increase (debit) Cash by $\$ 500$ and increase (credit) Accounts Payable by $\$ 500$.
D. Increase (debit) Accounts Receivable by $\$ 500$ and increase (credit) Unearned Revenue by $\$ 500$.
E. *Increase (debit) Cash by $\$ 500$ and increase (credit) Unearned Revenue by $\$ 500$.

10. The company has discovered that one customer cannot pay for the merchandise that they have purchased on credit. The correct entry to record this should be:
A. Increase (debit) Bad Debts Expense and decrease (credit) Accounts Receivable.
B. *Decrease (debit) the Allowance for Doubtful Accounts and decrease (credit) Accounts Receivable.
C. Increase (debit) Bad Debts Expense and increase (credit) the Allowance for Doubtful Accounts.
D. Decrease (credit) Accounts Receivable and increase (credit) the Allowance for Doubtful Accounts.
E. Increase Accounts Payable (credit) and decrease (debit) the Allowance for Doubtful Accounts.

11. As of December 31 Smith Company has Assets of $\$ 50,000$ and Owners Equity of $\$ 30,000$. What is the amount of total Liabilities if Revenue of $\$ 40,000$ and Expenses of $\$ 25,000$ were not yet closed to equity?
A. $* \$ 5,000$;
B. B. $\$ 10,000$;
C. C. $\$ 15,000$;
D. D. $\$ 20,000$;
E. E. $\$ 25,000$.

12. Select the item below that should be classified as Equity:
A. Accounts Receivable;
B. *Common Stock;
C. Merchandise Inventory;
D. Notes Payable;
E. Cost of Goods Sold. 
13. One accounting principle requires that the expenses of the business, incurred related to the effort of earning revenue, should be included on the same Income Statement as those revenues. That principle is called the:
A. *Matching principle;
B. Cost principle;
C. Revenue recognition principle;
D. Accrual accounting;
E. Periodicity.

14. Select the statement below that best describes an asset.
A. The cost of resources consumed in the process of earning revenue.
B. Creditor claims on corporate resources.
C. The gross increase in owner's equity resulting from business activities entered into for the purpose of earning income.
D. * Resources owned by a business that provide future benefits.
E. The ownership claim on total resources.

15. Select the statement below that best describes a liability.
A. The ownership claim on total resources.
B. *Claims on business resources by creditors.
C. The gross increase in owner's equity resulting from business activities entered into for the purpose of earning income.
D. Resources owned by a corporation that provide future benefits in cash.
E. The cost of resources consumed in the process of earning revenue.

16. Select the statement below that best describes owners' equity.
A. The cost of resources consumed in the process of earning revenue.
B. Creditors' claims on corporate resources.
C. The gross increase in owner's equity resulting from business activities entered into for the purpose of earning income.
D. Resources owned by a business that provide future benefits.
E. *The ownership claim on total resources of the business.

17. Select the statement below that best describes revenue.
A. The cost of resources consumed in the process of earning revenue.
B. Creditors' claims on corporate resources.
C. *The increase in assets or decrease in liabilities resulting from sales of merchandise or performance of services.
D. Resources owned by a business that provide future benefits.
E. The ownership claim on total resources. 
18. Select the statement below that best describes expenses.
A. *The cost of resources consumed in the process of earning revenue.
B. Creditors' claims on corporate resources.
C. The increase in assets or decrease in liabilities resulting from sales of merchandise or performance of services.
D. Resources owned by a business that provide future benefits.
E. The ownership claim on total resources.
$*=$ correct answer.

Background Information (Select the answer that is closest). By taking this survey you indicate that you have received an informed consent form and agree to be part of this research study. You may choose not to complete the survey or withdraw at any time.

19. My cumulative grade point average is:
A. $<2.0$;
B. 2.0 ; C. 2.25 ;
D. 2.5 ; E. 2.75

20. My cumulative grade point average is:
A. $3.0 ;$
B. 3. 25; C. 3.5 ; D. 3
D. 3.75 ; E. 4.0

21. My grade in the first accounting course (ACC201) was:
A. $<2.0$;
B. 2.0 ;
C. 2.25 ; D. 2
D. 2.5 ; E. 2.75

22. My grade in the first accounting course (ACC201) was:
A. $3.0 ;$
B. 3. 25; C.
C. $3.5 ; \mathrm{D} .3$
D. 3.75 ; E. 4.0

23. I plan on majoring in:
A. Accounting or Accounting Information Systems;
B. Economics;
C. Entrepreneurship;
D. Finance or Real Estate, Law;
E. Hospitality Services Administration.

24. I plan on majoring in:
A. Human Resources Management;
B. Management;
C. Management Information Systems;
D. Marketing, Logistics, or Purchasing and Supply Management.

25. My gender is: A. Male; B. Female. 
Test Question Summary

\begin{tabular}{|c|c|c|c|c|}
\hline \multirow{2}{*}{$\begin{array}{l}\text { Q\# } \\
1\end{array}$} & \multicolumn{2}{|c|}{$\begin{array}{l}\text { Index of } \\
\text { Discrimination }\end{array}$} & \multicolumn{2}{|c|}{$\begin{array}{l}\text { Index of } \\
\text { Difficulty }\end{array}$} \\
\hline & 0.600 & (Very Good) & 0.633 & (Optimum) \\
\hline 2 & 0.733 & (Very Good) & 0.633 & (Optimum) \\
\hline 3 & 0.733 & (Very Good) & 0.567 & (Optimum) \\
\hline 4 & 0.600 & (Very Good) & 0.367 & (Optimum) \\
\hline 5 & 0.467 & (Very Good) & 0.633 & (Optimum) \\
\hline 6 & 0.133 & (Poor) & 0.133 & (Very Hard) \\
\hline 7 & 0.600 & (Very Good) & 0.567 & (Optimum) \\
\hline 8 & 0.533 & (Very Good) & 0.667 & (Optimum) \\
\hline 9 & 0.733 & (Very Good) & 0.633 & (Optimum) \\
\hline 10 & 0.133 & (Poor) & 0.200 & (Hard) \\
\hline 11 & 0.467 & (Very Good) & 0.233 & (Hard) \\
\hline 12 & 0.400 & (Very Good) & 0.733 & (Easy) \\
\hline 13 & 0.333 & (Good) & 0.367 & (Optimum) \\
\hline 14 & 0.333 & (Good) & 0.833 & (Easy) \\
\hline 15 & 0.333 & (Good) & 0.500 & (Optimum) \\
\hline 16 & 0.667 & (Very Good) & 0.467 & (Optimum) \\
\hline 17 & 0.333 & (Good) & 0.833 & (Easy) \\
\hline 18 & 0.400 & (Very Good) & 0.800 & (Easy) \\
\hline
\end{tabular}

We tested the construct validity of our test by examining the relationships between the student's responses to different test items and their overall test results. An Index of Discrimination, shown above, was used. It describes the degree to which students with a high overall test score also got a particular question correct versus those students who got the question right but did poorly on the overall exam. The index is a point-biserial correlation coefficient ranging from 1.0 to -1.0 , where 1.0 indicates a perfect correlation and -1.0 indicates a negative correlation between answering the question correctly and getting a perfect score on the test. Of the questions included in the test, 12 were ranked very good, 4 were good, and 2 received poor rankings because of the difficult nature of the questions.

Content validity was tested by verifying that the topics of the questions were the essential topics covered in major introductory financial texts. They covered application of accrual accounting concepts addressing events related to the exchange, sale, consumption and distribution of resources. The treatment of these transactions is covered the most commonly used introduction to financial accounting texts. 
Appendix 3. Demographic Information

College Major

\begin{tabular}{|l|l|l|}
\hline Major & Frequency & Percentage \\
\hline Accounting & 33 & $23 \%$ \\
\hline Economics & 3 & $2 \%$ \\
\hline Entrepreneaurship & 2 & $1 \%$ \\
\hline Finance & 16 & $11 \%$ \\
\hline Human Resources & 10 & $7 \%$ \\
\hline Hospitality & 3 & $2 \%$ \\
\hline Information Systems & 13 & $9 \%$ \\
\hline Management & 20 & $14 \%$ \\
\hline Marketing & 45 & $31 \%$ \\
\hline Total & 145 & $100 \%$ \\
\hline
\end{tabular}

Class in College

\begin{tabular}{|l|l|l|}
\hline Class & Frequency & Percentage \\
\hline Sophomore & 70 & $48 \%$ \\
\hline Junior & 62 & $42 \%$ \\
\hline Senior & 14 & $10 \%$ \\
\hline Total & 146 & $100 \%$ \\
\hline
\end{tabular}

\section{Copyright Disclaimer}

Copyright for this article is retained by the author(s), with first publication rights granted to the journal.

This is an open-access article distributed under the terms and conditions of the Creative Commons Attribution license (http://creativecommons.org/licenses/by/3.0/). 